\section{Sergiy Oveckiy, Yurii Melnychenko, Lesia Moroz, Yaroslav Yakymechko}

\title{
DEVELOPMENT OF MARINE GAS HYDRATE DEPOSITS WITH ALTERNATIVE USE OF THE POTENTIAL OF THE GAS TRANSPORT SYSTEM ON THE EXAMPLE OF UKRAINE
}

The object of research is the use of a pipeline system for the production of methane and utilization of carbon dioxide. One of the most problematic areas in this scheme is the substantiation of the effectiveness and the possibility of using the existing pipeline system of countries that are gradually moving towards carbon neutrality of the economy based on the principles of sustainable development. In this case, these principles are implemented through the consumer's access to clean energy by burning gas obtained from offshore hydrate fields at thermal power plants with the simultaneous utilization of carbon dioxide.

In the course of the study, the methods of mathematical modelling of the development of offshore gas hydrate fields were used, which were developed earlier in the study of methane production from hydrate deposits by the replacement method. Comparison of the block diagram of the development of offshore gas hydrate fields using the existing pipeline system by means of logical analysis made it possible to establish not only the economic, but also the environmental effect.

Data have been obtained that the gas transmission system, provided that carbon dioxide is transported, can be effectively used at various stages of the development of offshore gas hydrate fields. This is due to the fact that the proposed development block diagram has a number of design features, in particular, the possibilities of using the gas transmission system at the stage of development, production and decommissioning of wells are taken into account.

This makes it possible to efficiently use carbon dioxide transported from power plants using the existing transport system to the development site of offshore hydrate deposits. Compared with similar known methods of carbon dioxide utilization, this provides the following advantages: alternative use of the existing pipeline system for the purpose of greening the technology of methane production from offshore hydrate deposits.

The principles considered in the work make it possible to dispose carbon dioxide in the form of a hydrate under the seabed. The achieved economic effect can be considered as income received from the sale of electricity produced at power plants, and quite obvious environmental effect.

Keywords: development of offshore hydrate deposits, greening of natural gas production technology, utilization of carbon dioxide.

Oveckiy, S., Melnychenko, Y., Moroz, L., Yakymechko, Y. (2021). Development of marine gas hydrate deposits with alternative use of the potential of the gas transport system of on the example of Ukraine. Technology Audit and Production Reserves, 4 (1 (60)), 54-57. doi: http://doi.org/10.15587/ 2706-5448.2021.237171

\section{Introduction}

The problem of using the gas transportation system in the world arose 10-15 years ago, when there was a need to move to carbon neutrality of the economy [1]. One possible use of the gas transmission system in the future is the utilization of carbon dioxide [1] (Ireland) or the delivery of hydrogen obtained by various means to the consumer [2] (Great Britain). The prospects of using a pipeline system for biomethane transportation are also considered [3]. Some researchers [4] (United States of America) point out the significant socio-economic risks due to the insufficient load of the existing gas pipeline system due to the transition of the economy to a low-carbon basis. Especially valuable for both the world and Ukraine is the study [5] (Belgium) on the possibility of using the gas transmission system for gas utilization and storage and the connection of this process with electricity generation. In Ukraine, where there are a large number of thermal power plants, developed gas transmission systems and the Black Sea with highly promising natural gas resources in hydrate fields, we can offer an interesting comprehensive solution that will be attractive to many countries. 
The opening of the Nord Stream 2 gas pipeline can have very difficult consequences for Ukraine, as about $3 \%$ of gross domestic product provides for the transit of Russian gas to Western Europe through Ukraine [6]. The cessation or even reduction of gas transportation volumes may lead to the bankruptcy of GTS Ukraine Operator LLC (Kyiv, Ukraine) in the near future. However, there are opportunities to reduce or eliminate such consequences by alternative use of the potential of the gas transmission system [7]. One of the possible prospects for such an application of the gas transmission system is the transportation of carbon dioxide [1], in order to dispose of it as the main environmentally harmful waste from large producers, in particular, thermal power plants.

An option that will bring not only environmental but also economic effect is the use of carbon dioxide to extract hydrocarbons, for example, to maintain reservoir pressure in the process of field development [8]. Another alternative to the use of carbon dioxide is the possibility of replacing methane in the crystalline structures of gas hydrates [9] of the Black Sea bottom. In this case, the volumes of utilized carbon dioxide and methane obtained in the process of replacing can be ten times larger than when using the technology of maintaining reservoir pressure. Therefore, the development of the technological process of methane extraction from gas hydrate fields is an urgent issue, if it is based on the use of the pipeline system of Ukraine for the transportation of carbon dioxide.

Thus, the object of research is the use of a pipeline system for methane production and carbon dioxide utilization. And the aim of research is to substantiate the possibility of using the gas transmission system for the development of offshore gas hydrate fields.

\section{Methods of research}

The research on the development of offshore gas hydrate fields is based on the methods described in [10]. The main hypothesis of the study is that the gas transportation system of Ukraine under the condition of carbon dioxide transportation can be effectively used at different stages of development of marine gas hydrate fields [11]

The following scientific methods were used in the study:

- method of classification - in

determining the objects of energy and transport infrastructure for the implementation of the developed block diagram;

- method of functional-cost analysis - in the study of the conceptual model of development of marine hydrate deposits at the stages of development, production and decommissioning of wells.

\section{Results of research and discussion}

The conceptual model of marine hydrate field development (Fig. 1) begins with the stage of obtaining data through geological exploration.

Exploration of marine gas hydrate deposits is based on the bottom manifestations of natural methane discharge, the largest of which are bottom mud volcanoes. Near such manifestations, as a rule, bottom or under the seabed hydrate deposits are found at a slightly greater depth [12].

Transfer of formation fluids to the surface should be carried out by means of wells. The depth of sea hydrates under the bottom does not exceed $1200 \mathrm{~m}$. The depth of the water area in the Black Sea for the existence of hydrates from $500 \mathrm{~m}$. Then the total length of the water column and the bottom of the casing will be approximately $1700 \mathrm{~m}$.

Features of drilling wells for the development of hydrate deposits are determined by the need to preserve the uncased wellbore through the dissociation of hydrates in the bottomhole area, taking into account:

1) increase in temperature due to friction of the tool and the drill string;

2) exposure to chemically active components of drilling mud.

These issues are solved by regulating the composition of the drilling fluid, namely the introduction of lubricating admixtures that reduce the coefficient of friction on the ice-like surface of the hydrate and limiting the use of mineralized compositions of drilling fluids.

Further tactics for the development of hydrate deposits are associated with the presence of underwater mud volcanoes.
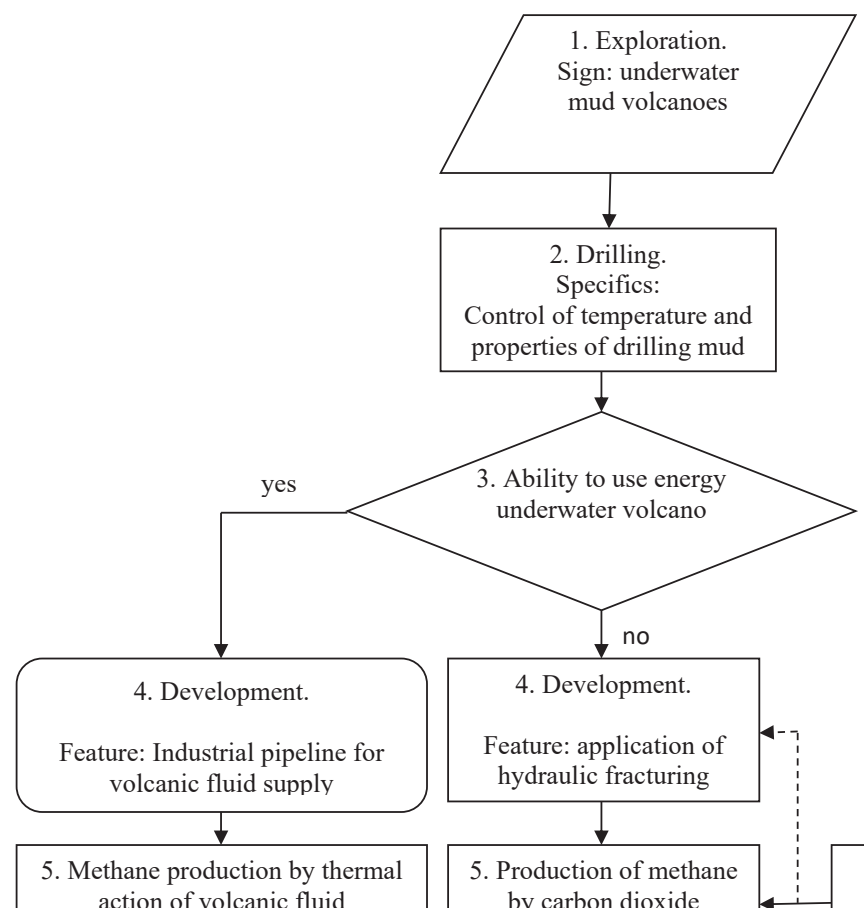
action of volcanic fluid
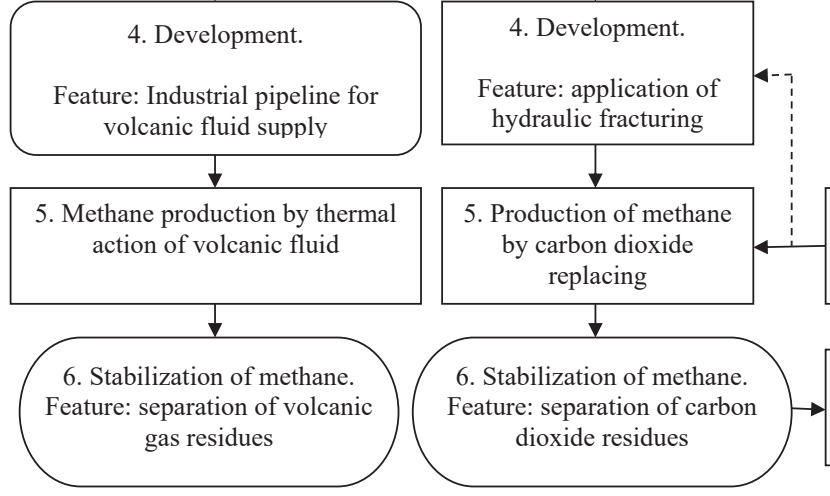

portation of methane 8. Electricity generation and CHP and TPP Feature: capture, collection and preparation of carbon dioxide

Fig. 1. Conceptual block diagram of the development of marine gas hydrate fields 
The technology of supply of these fluids by industrial pipelines to the surface bottom outlets of gas hydrates for their dissociation can be used if:

- such volcanoes have high fluid productivity;

- fluid temperature is quite high;

- distance to the deposit is small and allows the supply

of fluid with allowable heat loss.

It should be borne in mind that to limit the ingress of suspended particles of mud of the volcano to the deposit drilled in the mouth of the volcano wells of small depth, must be inclined in the mouth. The authors of [10] hypothesized that under certain hydrodynamic conditions surface bottom hydrates can serve as a non-permeable seal rock for free methane output, so with sufficient methane flow rates it is possible to operate these deposits without drilling special wells.

If it is impossible to use the energy of underwater volcanoes to dissociate bottom and under the seabed deposits of hydrates, due to the long distance, too low temperature of volcanic fluid, etc., it is necessary to use other production methods. The main among these methods for marine deposits was the method of replacing [11], which has a number of advantages, in particular: - preservation of the rock skeleton with the elimination of the risk of bottom landslides, because sea hydrates, in contrast to the land have a much lower content of solid impurities and their crystals act as the main structure-forming matter;

- control of the main filtration characteristics by determining the appropriate technological parameters of the replacement process.

The technological process of development involves the use of fracturing in the case if the main deposit is at a depth of more than $500 \mathrm{~m}$, which makes it possible to avoid artificial gas griffins on the bottom surface. The purpose of fracturing is traditional - to create a network of artificial cracks to increase the total inflow of methane, as well as increase the area of contact with the replacement gas. In this case, as a proppant can be used not only sand but also hydrateforming gas [13], which at a sufficiently high pressure and low temperature can form hydrates of fixation. In the process of well development by hydraulic fracturing, hydrogen sulfide hydrates [11] have the advantage of being more resistant to pressure drop and temperature increase. However, currently there is no necessary equipment to increase the concentration of hydrogen sulfide obtained from deep water. Hydrogen sulfide is formed at a depth of $200-300 \mathrm{~m}$ in inland seas with anomalous gas regime in some countries, including Ukraine. Therefore, for the most part, most countries in the world will now have to use carbon dioxide as a substitute gas in the extraction of methane from gas hydrate fields.

Methane obtained from gas hydrate fields is used to generate electricity at thermal power plants (TPP) or combined heat and power (CHP) plants. The carbon dioxide formed in the production process is captured and sent in the opposite direction for substitution in the marine gas hydrate deposit. Methane and carbon dioxide form hydrates of the first type, filling large and small cavities of crystals [11], which, given the difference in molecular weight, theoretically allows to utilize 2.75 times more mass of carbon dioxide than methane.

Transportation of carbon dioxide to the marine deposit of hydrate is a technically difficult task, primarily due to the aggressiveness of this gas in relation to the equipment of existing pipelines, in particular its sealing elements.

It is necessary to solve the problems of carbon dioxide utilization on the principles of sustainable development - to get the maximum satisfaction of consumer needs without harming the environment, so let's define the features of this process on a specific example in Ukraine.

The nearest promising gas hydrate field can be considered deposits located near the volcano Odessa (Ukraine), Fig. 2. Laying of underwater pipelines to this area is possible with the use of already developed and unrealized projects of the pipeline transport system. In particular, to the Odessa gas field partly according to the design options of the route 2,3 , 4 , 5, or using long-term plans for the development of hydrocarbon fields near the Zmiyinyy Island.

At the first stages of development, especially during the development of wells, there is enough capacity of Odessa CHP, with an electric capacity of $68 \mathrm{MW}$ (natural gas consumption of about 6800 cubic meters). If to use the existing pipeline system, you will have to lay no more than $50 \mathrm{~km}$ of land section of the pipeline. When increasing the flow rate, it is necessary to use the nearest power plants (Fig. 3) - Zaporizhzhia TPP with a capacity of $2400 \mathrm{MW}$ (consumption of about 240 thousand cubic meters of natural gas). Otherwise, it is possible to use Trypillia TPP with a capacity of $600 \mathrm{MW}$ (consumption of about 60 thousand cubic meters of natural gas).

These TPPs are in close proximity to the main routes of the pipeline system of Ukraine (Fig. 4), so they will not require laying long sections of supply pipelines and can be effectively used for the proposed scheme (Fig. 1).

In addition, the calculation of the economic efficiency of this technological solution must be carried out not only taking into account the amount of electricity produced, but also a certain environmental effect from the utilization of carbon dioxide.

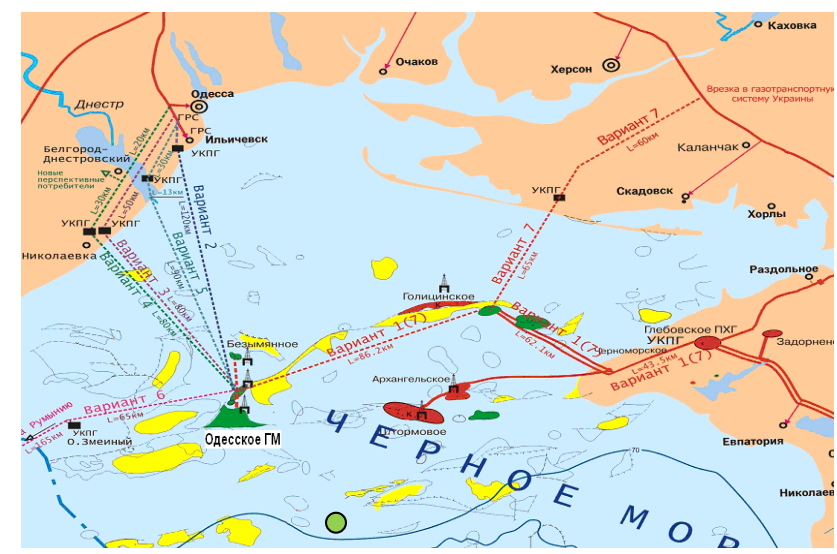

Fig. 2. Location of a promising area around the mud volcano Odessa (marked with a green circle)

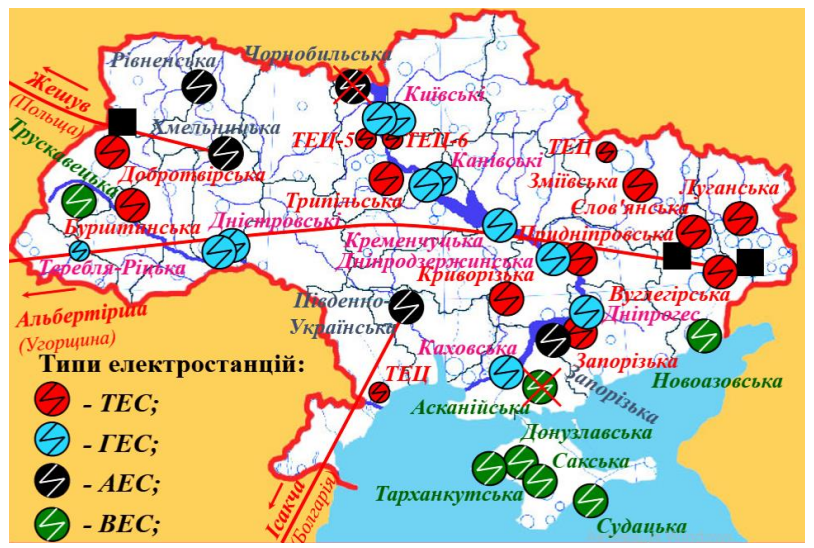

Fig. 3. Location of power plants of Ukraine [14] 


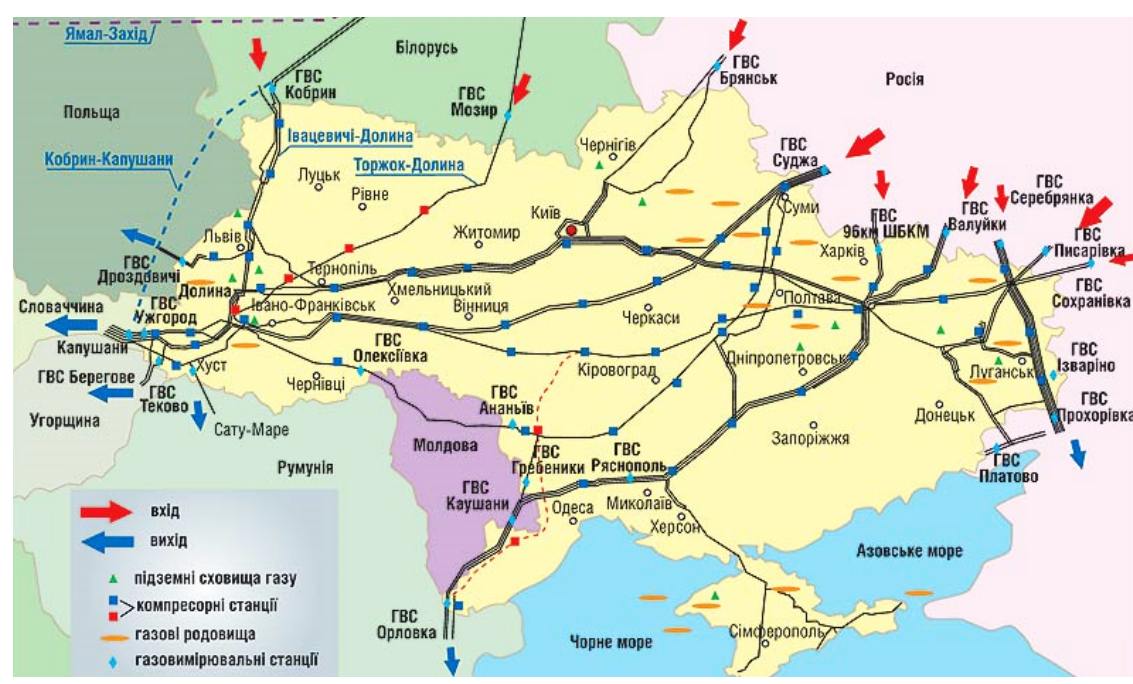

Fig. 4. Scheme of the pipeline system of Ukraine [15]

228, 149-166. doi: http://doi.org/10.1016/ j.apenergy.2018.06.037

5. Odetayo, B., Kazemi, M., MacCormack, J., Rosehart, W. D., Zareipour, H., Seifi, A. R. (2018). A Chance Constrained Programming Approach to the Integrated Planning of Electric Power Generation, Natural Gas Network and Storage. IEEE Transactions on Power Systems, 33 (6) 6883-6893. doi: http://doi.org/10.1109/ tpwrs.2018.2833465

6. White, M. (2020). Nord Stream 2 spells pain for Ukraine. Global Trade Reviere, 18 (1) Available at: https://www.gtreview.com/ magazine/volume-18-issue-1/nord-stream2-spells-pain-ukraine/

7. Lu, H., Ma, X., Huang, K., Fu, L., Azimi, M. (2020). Carbon dioxide transport via pipelines: A systematic review. Jour nal of Cleaner Production, 266, 121994 doi: http://doi.org/10.1016/j.jclepro. 2020.121994

For this purpose, for example, the approaches of the Kyoto Protocol [16] can be used, according to which a country that reduces emissions can sell its excess quota to other countries. Ukraine managed to do it at a price of more than 4 euros per ton of carbon dioxide.

\section{Conclusions}

The study shows the principles of alternative use of the existing pipeline system of Ukraine in order to green the technology of methane extraction from marine hydrate deposits, which allow to dispose carbon dioxide in the form of hydrate under the seabed. The achieved economic effect can be considered as the profit received from the sale of electricity obtained at power plants, and the obvious environmental effect. The developed block diagram can provide zero-waste electricity production by Zaporizhzhia TPP with utilization of more than 240 thousand cubic meters of carbon dioxide and Trypillia TPP with utilization of more than 60 thousand cubic meters of carbon dioxide per day.

The results of the study will be useful for countries that have coasts washed by deep waters of the seas and oceans (more than $500 \mathrm{~m}$ deep), in the implementation of the main stages of development of offshore hydrate gas fields, which can use carbon dioxide for production and development of wells. The developed methodology allows to assess the adequacy of the available capacity of thermal power plants and the existing gas transmission system of a particular country for economically and environmentally efficient production of gas from marine hydrate fields.

\section{References}

1. Hickey, C., Deane, P., McInerney, C., Ó Gallachóir, B. (2019) Is there a future for the gas network in a low carbon energy system? Energy Policy, 126, 480-493. doi: http://doi.org/10.1016/ j.enpol.2018.11.024

2. Dodds, P. E., McDowall, W. (2013). The future of the UK gas network. Energy Policy, 60, 305-316. doi: http://doi.org/ 10.1016/j.enpol.2013.05.030

3. Singlitico, A., Goggins, J., Monaghan, R. F. D. (2019). The role of life cycle assessment in the sustainable transition to a decarbonised gas network through green gas production. Renewable and Sustainable Energy Reviews, 99, 16-28. doi: http:// doi.org/10.1016/j.rser.2018.09.040

4. Feijoo, F., Iyer, G. C., Avraam, C., Siddiqui, S. A., Clarke, L. E., Sankaranarayanan, S. et. al. (2018). The future of natural gas infrastructure development in the United states. Applied Energy,

8. Zheng, S., Li, H., Yang, D. (2013). Pressure maintenance and improving oil recovery with immiscible $\mathrm{CO}_{2}$ injection in thin heavy oil reservoirs. Journal of Petroleum Science and Engineering, 112, 139-152. doi: http://doi.org/10.1016/j.petrol.2013.10.020

9. Pandey, J., Solms, N. (2019). Hydrate Stability and Methane Recovery from Gas Hydrate through CH4-CO2 Replacement in Different Mass Transfer Scenarios. Energies, 12 (12), 2309. doi: http://doi.org/10.3390/en12122309

10. Ovetska, O., Ovetskyi, S., Vytiaz, O. (2021). Conceptual principles of project management for development of hydrate and other unconventional gas fields as a component of energy security of Ukraine. Gas Hydrate Technologies: Global Trends, Challenges and Horizons. Dnipro, 230, 01021. doi: http://doi.org/10.1051/e3sconf/202123001021

11. Oveckiy, S., Savchuk, V. (2016). A method developed to increase technological and ecological efficiency of gas production from hydrate deposits. Eastern-European Journal of Enterprise Technologies, 3 (10 (81)), 41-47. doi: http://doi.org/10.15587/17294061.2016 .72545

12. Shnyukov, E. F., Kobolev, V. P., Pasynkov, A. A.; Gozhik, P. F. (Ed.) (2013). Gazoviy vulkanizm Chernogo morya. Kiyv: Logos, 383.

13. Andrews, J. W. (2020). Hydrogen production and carbon sequestration by steam methane reforming and fracking with carbon dioxide. International Journal of Hydrogen Energy, 45 (16), 9279-9284. doi: http://doi org/10.1016/j.ijhydene.2020.01.231

14. Poznachennia na konturnii karti Ukrainy naibilshykh elektrostantsii ta poiasnennia chynnykiv yikh rozmishchennia. Na Urok. Available at: https://naurok.com.ua/test/praktichna-robota-5-poznachennyana-konturniy-karti-ukra-ni-naybilshih-elektrostanciy-ta-poyasnennya-chinnikiv-h-rozmischennya-707205.html

15. Hazotransportna systema Ukrainy. Vikipediia. Available at: https:// uk.wikipedia.org/wiki/Газотранспортна_система_України

16. Kumazawa, R., Callaghan, M. S. (2010). The effect of the Kyoto Protocol on carbon dioxide emissions. Journal of Economics and Finance, 36 (1), 201-210. doi: http://doi.org/10.1007/s12197-010-9164-5

$\square$ Sergiy Oveckiy, PhD, Associate Professor, Department of Petroleum Production, Ivano-Frankivsk National Technical University of Oil and Gas, Ivano-Frankivsk, Ukraine, ORCID: https://orcid.org/ 0000-0002-3804-8638,e-mail: serhii.ovetskyi@nung.edu.ua

Yurii Melnychenko, PhD, Associate Professor, Department of Petroleum Production, Ivano-Frankivsk National Technical University of Oil and Gas, Ivano-Frankizsk, Ukraine, ORCID: https://orcid.org/ 0000-0002-5857-7203, e-mail: yurii.melnychenko@nung.edu.ua

Lesia Moroz, PhD, Associate Professor, Department of Petroleum Production, Ivano-Frankivsk National Technical University of Oil and Gas, Ivano-Frankivsk, Ukraine, ORCID: https://orcid.org/00000002-5183-4940, e-mail: mlb81@ukr.net

Yaroslav Yakymechko, PhD, Associate Professor, Department of Petroleum Production, Ivano-Frankizsk National Technical University of Oil and Gas, Ivano-Frankivsk, Ukraine, ORCID: https://orcid.org/ 0000-0002-4406-0094, e-mail: jarykjj@ukr.net

$\triangle$ Corresponding author 